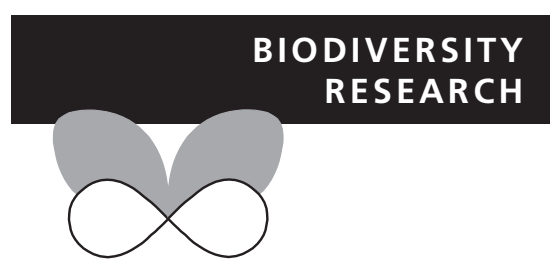

\title{
Introduction effort, climate matching and species traits as predictors of global establishment success in non-native reptiles
}

\author{
Peter J. Mahoney ${ }^{1 \star}$, Karen H. Beard ${ }^{1}$, Andrew M. Durso ${ }^{2}$, Aimee G. \\ Tallian $^{1}$, A. Lexine Long ${ }^{3}$, Ryan J. Kindermann ${ }^{1}$, Nicole E. Nolan ${ }^{1}$, \\ Daniel Kinka ${ }^{1}$ and Harrison E. Mohn ${ }^{3}$
}

\begin{abstract}
${ }^{1}$ Department of Wildland Resources and the Ecology Center, Utah State University, Logan, UT 84322-5230, USA, ${ }^{2}$ Department of Biology and the Ecology Center, Utah State University, Logan, UT 84322-5305, USA, ${ }^{3}$ Department of Watershed Sciences and the Ecology Center, Utah State University, Logan, UT 84322-5210, USA
\end{abstract}

${ }^{*}$ Correspondence: Peter J. Mahoney, Department of Wildland Resources and the Ecology Center, Utah State University, Logan, UT 84322-5230, USA.

E-mail: pmahoney29@gmail.com

\begin{abstract}
Aim Non-native reptiles are often detrimental to native communities and ecosystems and can be extremely difficult to manage once established. Thus, there is considerable interest in predicting the likelihood of establishment of nonnative reptiles. We assessed three hypotheses describing possible factors contributing to the successful establishment of introduced reptiles in an effort to better identify potential invaders.
\end{abstract}

Location Worldwide.

Methods Using a global invasion database (1307 introductions of 398 species) and Bayesian generalized linear mixed models, we tested the relative importance of event-level (e.g. propagule pressure), location-level (e.g. climate matching) and species-level (e.g. parthenogenesis) factors in reptile establishment success.

Results The factors that positively influenced establishment success included: (i) Event-level: longer time since initial introduction, greater number of introduction events and intentional introductions; (ii) Location-level: smaller differences in latitude between native and introduced ranges and the presence of native congeners in the introduced range; and (iii) Species-level: smaller body size, herbivores, larger native range size, parthenogenesis and high fecundity.

Main conclusions We found that location-level factors were most important in describing reptile establishment success, followed by event- and species-level factors, respectively. This pattern matches closely with what others have found in a variety of vertebrate taxa. However, the importance of species traits may be underestimated considering the insufficient knowledge of reptile life history within introduced ranges. Importantly, individual variables from all three hypotheses contributed to global reptile establishment. Managers should be especially cognizant of small herbivorous and fecund reptiles that are frequently introduced into areas with a strong climate match to their native range. Further, parthenogenesis greatly facilitated establishment, indicating that obligate parthenogenetic species may become ubiquitous through modern globalized trade.

\section{Keywords}

Biological invasions, body size, environmental tolerance, herpetofauna, nonnative, parthenogenesis, propagule pressure, reptile. 


\section{INTRODUCTION}

Humans have long facilitated the transport of non-native species to novel environments. Understanding the factors that contribute to a near $50 \%$ establishment success of nonnative vertebrate species (Jeschke \& Strayer, 2005) has become a central theme in invasion ecology (Kolar \& Lodge, 2001; Hayes \& Barry, 2008). Establishment success is often defined in the context of three, scale-dependent sets of factors: (i) characteristics of the introduction event, (ii) characteristics of the introduced location and (iii) species traits (Hayes \& Barry, 2008; Rago et al., 2012). Evaluating establishment in the context of one or two of these sets may lead to biased conclusions about the importance of specific factors if other confounding, yet important, factors are not considered. Therefore, elucidating the relative importance of these sets of factors necessitates a complete evaluation of all known drivers of non-native establishment. The results from such an endeavour will help to provide managers with a predictive tool for measuring non-native establishment risk while advancing our understanding of species range expansion.

The characteristics of an introduction event (i.e. eventlevel factors) are often major drivers of establishment success (Lockwood et al., 2005). Event-level factors are generally population attributes that affect persistence and include the number of introduction events and the number of individuals introduced (i.e. propagule pressure; Lockwood et al., 2005). However, they may also include the time since introduction because of possible time lags associated with establishment (Mack et al., 2000; Barney \& Whitlow, 2008). Often, little is known about event-level characteristics due to the difficult nature of collecting event-specific information, especially for unintentionally introduced species (Lockwood et al., 2005). However, where data exist, characteristics of the event have been shown to impact the establishment success of many vertebrates, both singly (Forsyth \& Duncan, 2001; Blackburn et al., 2013) and when considered with nonevent-specific factors (Simberloff, 2009; Rago et al., 2012; van Wilgen \& Richardson, 2012).

The characteristics of an introduced location (i.e. location-level factors) are extrinsic factors associated with the novel landscape. Most important is the degree to which the introduced location 'resembles' a species' native range (i.e. climate matching) as greater resemblance typically increases the likelihood of establishment (Bomford et al., 2009b). Common metrics include measures of geographic separation (Rago et al., 2012) and differences in climatic regimes (Bomford et al., 2009b). However, other factors may be correlated with the extent a species is pre-adapted for invading novel environments, and include diversity of habitat (Blackburn et al., 2009), presence of congeners (Ferreira et al., $2012 \mathrm{~b}$ ) and whether or not the introduction occurs on an island (Cassey, 2003). Recent evidence suggests that location-level factors are as important as event-level factors in determining the establishment success of introduced populations (Rago et al., 2012; van Wilgen \& Richardson, 2012; Poessel et al., 2013).

Finally, species-level life-history traits (i.e. species-level factors) are also important in non-native establishment success (Kolar \& Lodge, 2001; Marchetti et al., 2004; Hayes \& Barry, 2008), but are often considered less important than eventand location-specific factors (Rago et al., 2012; van Wilgen \& Richardson, 2012). Species with traits that facilitate rapid population growth and persistence, despite founder effects, appear better adapted for establishing novel populations (Lockwood et al., 2005; Blackburn et al., 2009). Species-level factors often include measures of reproductive output (Blackburn et al., 2009; van Wilgen \& Richardson, 2012), body size (Allen et al., 2013) and traits that influence Allee effects (e.g. dichromatism, Blackburn et al., 2009). In addition, trophic differences (e.g. herbivore, carnivore) can lead to important variation in extinction risk (Purvis et al., 2000) and thus may be relevant to establishment success.

It is increasingly evident that non-native reptiles have the potential to exert substantial direct and indirect effects on ecosystems (e.g. Fritts \& Rodda, 1998; Traveset \& Riera, 2005; Dorcas et al., 2012; Rogers et al., 2012). Additionally, non-native reptiles are often extremely problematic and expensive to manage once established, if realistic management options exist at all (Engeman et al., 2011). Recent research on reptile introductions has identified climate matching, propagule pressure and phylogenetic relatedness between introduced and native species to be important predictors of non-native establishment success, but most of these studies were conducted at smaller regional scales (Bomford et al., 2009b; van Wilgen et al., 2009; Fujisaki et al., 2010; van Wilgen \& Richardson, 2011, 2012). In a recent meta-analysis, Hayes \& Barry (2008) were only able to include a single paper assessing reptile establishment success, and although more have been published since (Bomford et al., 2009b; Kraus, 2009; Ferreira et al., 2012a,b), none directly evaluate life history against other factors known to influence establishment success. The next logical step is to develop a more generalizable framework for understanding the factors contributing to reptile establishment success worldwide, with a particular emphasis on the relative influence of factors deemed important in other vertebrate taxa in the light of the unique natural history of reptiles.

Therefore, we assess three hypotheses pertaining to factors contributing to the successful establishment of non-native reptile globally (Table 1): (i) factors specific to the introduction event (event-level hypothesis), (ii) factors enabling species to cope with novel environments (location-level hypothesis) and (iii) species traits associated with population growth (species-level hypothesis; Table 1). We considered each hypothesis individually, and collectively, to test the relative importance of each within the context of reptile establishment worldwide. 


\section{P. J. Mahoney et al.}

Table 1 Variables used as fixed effects in a test of the relative influence of event-level, location-level and species-level factors on establishment success for reptiles worldwide

\begin{tabular}{|c|c|c|}
\hline Variable name & Value range & Source \\
\hline \multicolumn{3}{|l|}{ Event } \\
\hline $\begin{array}{l}\text { Time since first } \\
\text { introduction (years) }\end{array}$ & $3-7,009$ & Kraus (2009) \\
\hline $\begin{array}{l}\text { Number of prior } \\
\text { introductions }\end{array}$ & $1-314$ & Kraus (2009) \\
\hline Mode of introduction & $\begin{array}{l}\text { Accidental, } \\
\text { intentional, } \\
\text { unknown }\end{array}$ & Kraus (2009) \\
\hline \multicolumn{3}{|l|}{ Location } \\
\hline $\begin{array}{l}\text { Difference in mean PET } \\
\text { between introduced and } \\
\text { native ranges }\end{array}$ & $0.03-1470$ & $\begin{array}{l}\text { Trabucco \& } \\
\text { Zomer (2009) }\end{array}$ \\
\hline $\begin{array}{l}\text { Difference in centre point } \\
\text { latitude between } \\
\text { introduced and native } \\
\text { ranges }(\mathrm{m})\end{array}$ & $1430-7,207,000$ & $\begin{array}{l}\text { IUCN, The } \\
\text { Reptile } \\
\text { Database, and } \\
\text { WWF } \\
\text { Wildfinder } \\
\text { Database }\end{array}$ \\
\hline $\begin{array}{l}\text { Richness of congeners in } \\
\text { introduced range }\end{array}$ & $0-59$ & $\begin{array}{l}\text { Ferreira et al. } \\
(2012 b)\end{array}$ \\
\hline $\begin{array}{l}\text { Presence/absence of } \\
\text { congeners in introduced } \\
\text { range }\end{array}$ & $0 / 1$ & $\begin{array}{l}\text { Ferreira et al. } \\
(2012 \mathrm{~b})\end{array}$ \\
\hline $\begin{array}{l}\text { Introduced range was an } \\
\text { island }\end{array}$ & $0 / 1$ & $\begin{array}{l}\text { Ferreira et al. } \\
\text { (2012b) }\end{array}$ \\
\hline \multicolumn{3}{|l|}{ Species } \\
\hline Live bearer & $0 / 1$ & See Appendix S2 \\
\hline Mean adult body weight (g) & $0.4-160,000$ & See Appendix S2 \\
\hline $\begin{array}{l}\text { Mean adult snout-vent } \\
\text { length }(\mathrm{cm})\end{array}$ & $2.8-390$ & See Appendix S2 \\
\hline $\begin{array}{l}\text { Temperature-dependent sex } \\
\text { determination }\end{array}$ & $0 / 1$ & See Appendix S2 \\
\hline $\begin{array}{l}\text { Parthenogenesis (obligate/ } \\
\text { facultative; see text) }\end{array}$ & $0 / 1$ & See Appendix S2 \\
\hline $\begin{array}{l}\text { Mean gestation/incubation } \\
\text { time (days) }\end{array}$ & $5-731$ & See Appendix S2 \\
\hline $\begin{array}{l}\text { Annual fecundity (clutch } \\
\text { size } \times \text { clutches per year) }\end{array}$ & $1-108$ & See Appendix S2 \\
\hline Diet type & $\begin{array}{l}\text { Herbivore, } \\
\text { omnivore, } \\
\text { carnivore }\end{array}$ & See Appendix S2 \\
\hline Native range size $\left(\mathrm{km}^{2}\right)$ & $53.8-62,000,000$ & $\begin{array}{l}\text { IUCN, The } \\
\text { Reptile } \\
\text { Database, and } \\
\text { WWF } \\
\text { Wildfinder } \\
\text { Database }\end{array}$ \\
\hline
\end{tabular}

\section{METHODS}

\section{Main hypotheses and data compilation}

We investigated the non-native reptile species, and associated introductions, described in Kraus's (2009) database (see
Table 2 Breakdown of the number of introductions by order type. Mean species introductions represent the mean number of introductions per species within order type. SD, standard deviation

\begin{tabular}{|c|c|c|c|c|c|}
\hline Order type & Species & $\begin{array}{l}\text { Mean species } \\
\text { introductions } \\
(\mathrm{SD})\end{array}$ & Successful & Failed & Total \\
\hline Crocodilian & 6 & $3.7(4.1)$ & 3 & 19 & 22 \\
\hline Lizard & 205 & $3.1(5.4)$ & 444 & 183 & 627 \\
\hline Snake & 113 & $2.9(7.1)$ & 118 & 210 & 328 \\
\hline Chelonian & 74 & $4.5(8.4)$ & 143 & 187 & 330 \\
\hline Total & 398 & $3.3(6.5)$ & 708 & 599 & 1307 \\
\hline
\end{tabular}

Bomford et al., 2009b; Ferreira et al., 2012b; Rago et al., 2012; Poessel et al., 2013) using the taxonomy of The Reptile Database (Uetz \& Hallermann, 2008). Our completed database contained information on 1307 introductions of 398 species, of which 708 introductions were successful (Table 2, Appendix S1).

For the event-level hypothesis, we included data on the number of introduction events, the time since first introduction, and the mode of introduction for each species and introduced location (Kraus, 2009) (Table 1). Time since first introduction was calculated as the number of years as a species was first introduced relative to 2008. We simplified mode of introduction into a binary variable for intentional or unintentional introductions based on the classifications from Rago et al. (2012). For a given species where multiple introduction events occurred in a single location (i.e. one species record), the mode of introduction was designated intentional if any of the known introductions were classified as such. Ideally, we would have included the number of individuals released during each event, but these data do not exist for many of the introductions.

To collect location-level data (Table 1), we digitized native range distribution data using the following sources prioritized in order: the IUCN Redlist Database (http://www.iucnredlist.org/), the World Wildlife Foundation Wildfinder Database (http://worldwildlife.org/science/wildfinder/) and the Reptile Database (Uetz \& Hallermann, 2008). In a few cases, we used range maps from other sources if our primary sources appeared to be incorrect. We estimated native range size using ArcGIS (v10.0, ESRI 2011). We digitized introduced ranges based on Kraus (2009) and estimated differences in absolute centroid latitudes between native and introduced ranges. We generated mean annual potential evapotranspiration (PET) estimates for each native and introduced range (Trabucco \& Zomer, 2009).

For the species-level hypothesis, we started with a life-history trait database collected from primary sources and maintained at Utah State University (Myhrvold et al., 2014), which included data on adult snout-vent length (SVL), adult body mass, clutch size, clutches per year and gestation/ incubation time for select reptile species. We augmented this database by including diet type, reproductive mode, 
temperature-dependent sex determination (TDSD) and parthenogenesis. When possible, we incorporated missing life-history data using a combination of primary and grey literature (Appendix S2). We gave priority to the primary literature and averaged values from multiple sources when more than one value was found. For sex-specific traits (i.e. SVL and body mass), we prioritized data in the following order: females, sex not given and males.

\section{Analysis}

We used generalized linear mixed models (GLMMs) to test the three main hypotheses (Table 1). All models had a single binary response variable representing establishment success (1) or failure (0). We incorporated a random intercept for geographic region to account for unknown correlations associated with introduced regions. Additionally, we included random intercepts for species, nested within higher taxonomic group (i.e. crocodilian, lizard, snake and chelonian), to account for phylogenetic non-independence in biology and sampling effort (Sol et al., 2008). Although there was $a$ priori justification for including all three random effects, we tested their appropriateness in global and null models for each analysis using Bayesian deviance information criterion (DIC; Spiegelhalter et al., 2002).

We fit Bayesian GLMMs to our compiled data using weakly informative, multivariate normal priors $(\mu=0$, $\sigma=10^{8}$ ) for all fixed effects and expanded inverse Wishart priors $(\mathrm{V}=1, \mathrm{nu}=0.002$, alpha.mu $=0$, alpha. $\mathrm{V}=1000)$ for all random effects. We estimated posterior distributions using Markov Chain Monte Carlo simulation (MCMC) with a Gibbs sampler. We evaluated MCMC chain performance using trace diagnostics to eliminate the influence of starting values, ensure independence among samples and identify proper convergence for all parameter estimates. We generated posterior means, 95\% highest posterior density intervals $\left(\mathrm{HPDI}_{95}\right)$ and $\mathrm{pMCMC}$ values for each covariate. pMCMC is a Bayesian $P$-value measuring the proportion of MCMC samples falling above or below zero and generally produces consistent interpretations of significance as attained from 95\% HPDI. However, pMCMC provides an efficient way of identifying moderately supported variables for inclusion in later models ( $\mathrm{pMCMC}<0.25$ ). All modelling was conducted using the MCMCglmm (v2.17; Hadfield, 2010) and lme4 packages (v0.999375-42, Bates et al., 2011) in Program $\mathrm{R}$ (v2.15.0, R Development Core Team, 2012).

Due to incomplete data for some variables within the three main hypotheses, we performed separate analyses for each hypothesis to maximize our sample size (event level: 736 introductions by 295 species, location level: 1297 introductions by 396 species, species level: 867 introductions by 224 species; Table 1). A fourth and final analysis (hereafter the overall analysis) incorporated all covariates moderately supported ( $\mathrm{pMCMC}<0.25$; Table 3) within our models from the previous analyses to test the relative importance of each hypothesis. Analysing each hypothesis separately with the largest possible data set allowed us to identify any substantial deviations in covariate effect sizes after sub-setting the data for the overall analysis (overall: 653 introductions by 293 species). Each analysis examined a single global model to identify the relative importance of variables within each hypothesis. Variants of the global models were used to test for non-linearities by incorporating polynomials or transforming continuous covariates. The difference in mean PET and centroid latitude between native and introduced ranges, native range size, annual fecundity and gestation/incubation time were centred by their means and scaled by one standard deviation. The number of introduction events, mean adult SVL and mean adult body mass were $\log _{10}$-transformed. Global model variants were ranked by DIC, with non-linear terms or transformations retained if the coefficients appeared in the top model.

\section{Analysis limitations}

Many researchers have acknowledged that introduction data are biased towards successful establishment, limiting our ability to derive absolute probabilities of establishment success, and therefore predictive power, from establishment models (Sol et al., 2008). However, we can draw inference from our coefficient estimates provided there has been sufficient sampling of unsuccessful establishment attempts. In addition, our life-history data are derived from native populations, potentially biasing our predictions in scenarios where traits may deviate between native and introduced ranges.

\section{RESULTS}

\section{Event-level hypothesis}

All three event-level variables influenced the probability of successful establishment: time since initial introduction, number of introduction events and mode of introduction (Table 3). Results from the global model indicated that the odds of establishment increased with every year beyond initial introduction. Each additional prior introduction also increased the odds of establishment. Finally, the probability of successful establishment also increased if a species was intentionally introduced $(P=0.079)$.

\section{Location-level hypothesis}

Two location-level variables influenced the probability of establishment success: differences in absolute centroid latitude and the presence of congeners (Table 3). A polynomial for the difference in latitude was incorporated in model variants to test for non-linearities. The second-order term for difference in latitude was retained based on HPD95 and pMCMC values (Table 3), indicating a significant non-linear trend. The model indicated a strong negative relationship between an increase in the difference in latitude and establishment success, with the effect strengthening as the difference increased. 


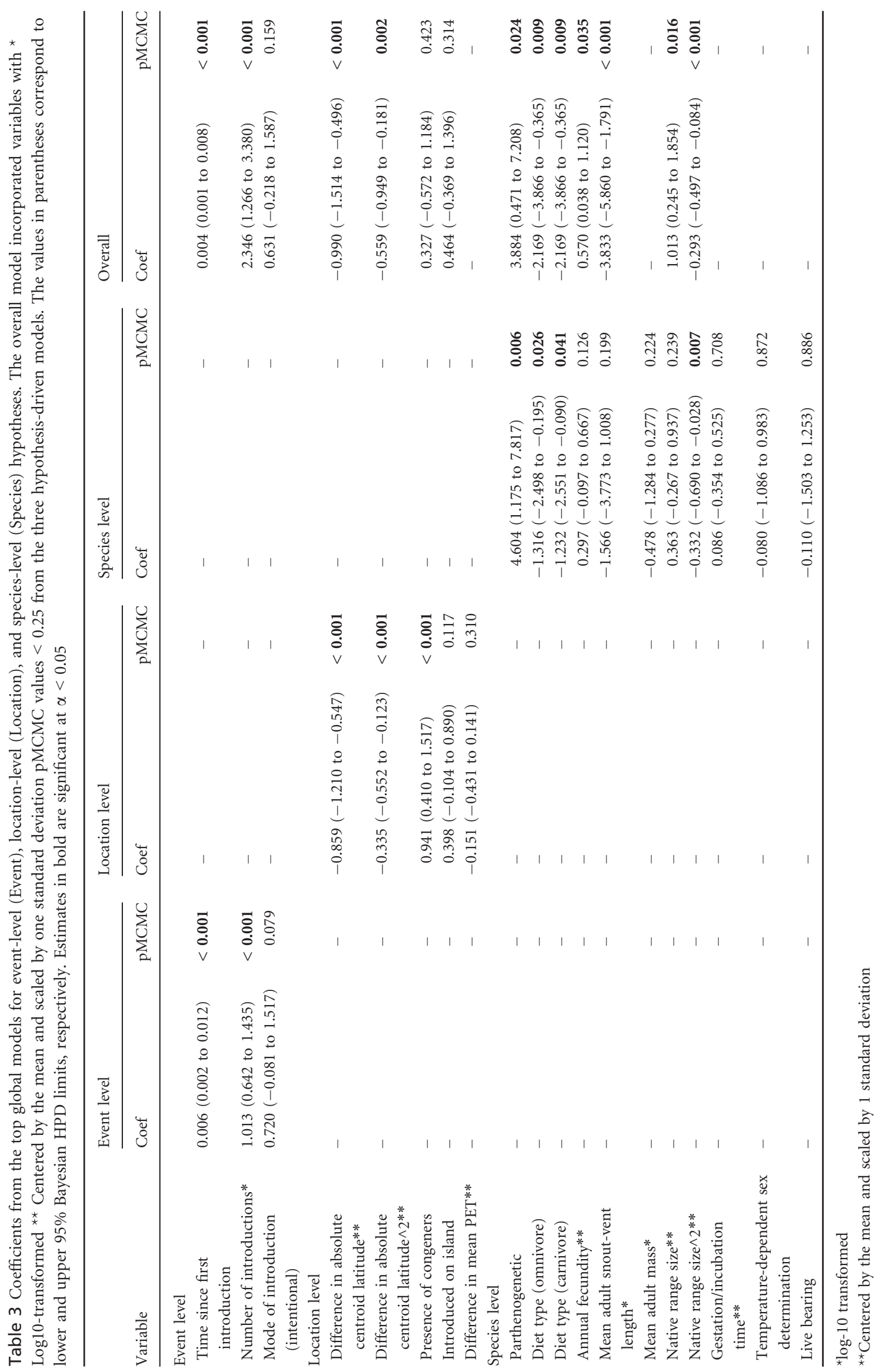


We tested congener richness and congener presence in two separate global models to identify which of the two congener variables best described the introduction data. There was some evidence for a non-linear relationship between congener richness and establishment success via significant firstand second-order polynomial terms, indicating that establishment success increased asymptotically with each additional congener species (results not shown). However, the simpler metric for congener presence appeared to be a stronger predictor of establishment success than congener richness $(\Delta \mathrm{DIC}>5)$; therefore, the global model with congener presence was retained, indicating that non-native species were more likely to establish in the presence of congeners. Introductions that occurred on islands were also more likely to be successful, but the effect of islands was only marginally supported in the global model $(\mathrm{pMCMC}=0.117)$.

\section{Species-level hypothesis}

Two species-level variables significantly influenced the probability of successful establishment: obligate parthenogenesis and diet type (Table 3). Obligate parthenogenesis increased the probability of establishment success relative to non-parthenogenetic species, as did both obligate and facultative parthenogenesis when considered together. Interestingly, parthenogenetic species occur at a higher frequency within the Kraus database relative to squamates at large. In total, at least 52 species $(0.5 \%)$ of squamates have been documented to have either obligate $\left(N_{\text {Obligate }} \sim 40 \mathrm{spp}\right.$.) or facultative ( $N_{\text {Facultative }} \sim 12$ spp.) parthenogenesis (Kearney et al., 2009; Booth et al., 2012). In our database, 14 of 398 (3.5\%) species have either obligate $(N=8)$ or facultative $(N=6)$ parthenogenesis. Overall establishment success rates for obligate and facultative parthenogenetic species were $91 \%$ $\left(N_{\text {Introductions }}=42\right)$ and $17 \% \quad\left(N_{\text {Introductions }}=23\right)$, respectively, as compared to $54 \%$ for all reptiles in our database $\left(N_{\text {Introductions }}=1307\right)$. Finally, omnivores and carnivores were less likely to establish than herbivores, but were not statistically different from one another $(\Delta \mathrm{DIC}<0.01)$.

There was also marginal support for native range size, annual fecundity and adult SVL. The coefficients for the native range size polynomial indicate an increase in the probability of establishment with an increase in range size, but the effect weakens at larger range sizes. The coefficient for annual fecundity also indicates more fecund species experience greater establishment success. Finally, smaller species appear more likely to establish than larger species. Due to concerns about collinearity between adult SVL and body mass, only SVL was considered in the overall model because of the stronger support for and larger effect size of SVL.

\section{Overall model}

The top global model identified a mixture of influential variables from the three respective hypotheses (Table 3, Fig. 1). The difference in latitude between native and introduced ranges, number of introduction events, time since first introduction, adult SVL and native range size was the most important predictors (based on pMCMC values). Covariates for parthenogenesis, diet type and annual fecundity also remained important, but with less confidence. For diet type, we combined carnivores and omnivores to reduce model complexity because there was no significant difference between these groups from the species-level model. All significant parameters generally matched the predictions of the individual hypotheses (Table 3).

To test the influence of extreme data points, we further subset the data by excluding outliers for number of introduction events ( $>50$ introductions, $\left.N_{\text {removed }}=4\right)$ and time since first introduction ( $>500$ years ago, $N_{\text {removed }}=10$ ) and ran two separate sub-models. By excluding species introduced more than 50 times, the log coefficient for the number of introduction events changed from 2.388 to 2.605 ( $\Delta \sim 10.6 \%)$. By excluding introductions that occurred more than 500 years ago, the coefficient for time since first introduction changed from 0.004 to 0.00005 ( $\Delta \sim 99.0 \%)$, indicating that these older introductions may be driving the significance of time since first introduction. However, as our results were consistent for the remaining coefficients with and without time since first introduction, we retained time within our overall model.

In addition, we removed the most frequently introduced parthenogenetic species (Ramphotyphlops braminus: $N_{\text {introductions }}=23$ ), which accounted for $55 \%$ of all obligate parthenogenetic introductions. Following the removal, the coefficient for parthenogenesis changed from 3.625 to 1.824 $(\Delta \sim 52.2 \%)$ and was no longer significant (pMCMC $=$ 0.327). However, the strength of the effect even after removing $R$. braminus suggested a true, positive signal for parthenogenesis, and the lack of statistical significance is likely attributable to a small sample size following the subset $(N=19)$.

Finally, we re-ran three sub-models, incorporating only the variables previously deemed important and using only the subset of data from the overall analysis (Table 3). Ranking the overall model, sub-models and null model using DIC indicated a similar relative importance of the respective hypotheses as described in the overall model (Table 4).

\section{Random effects}

Our primary objective was to identify the factors contributing to reptile establishment success as a group, rather than emphasize how they operate at finer taxonomic scales; thus, our methods necessitated the inclusion of taxonomic random effects to account for variation between and lack of independence within higher taxonomic groupings. DIC model rankings strongly supported the inclusion of all three random effects (geographic region, higher taxonomic group and species; $\Delta \mathrm{DIC}>10$ ). In the overall model, the greatest amount of variation was captured by higher taxonomic group $(\mu=0.314, \quad$ SE $=0.004)$, followed by species $(\mu=0.272$, $\mathrm{SE}=0.002)$, suggesting there was significant variation within and between species and higher taxonomic groups. 


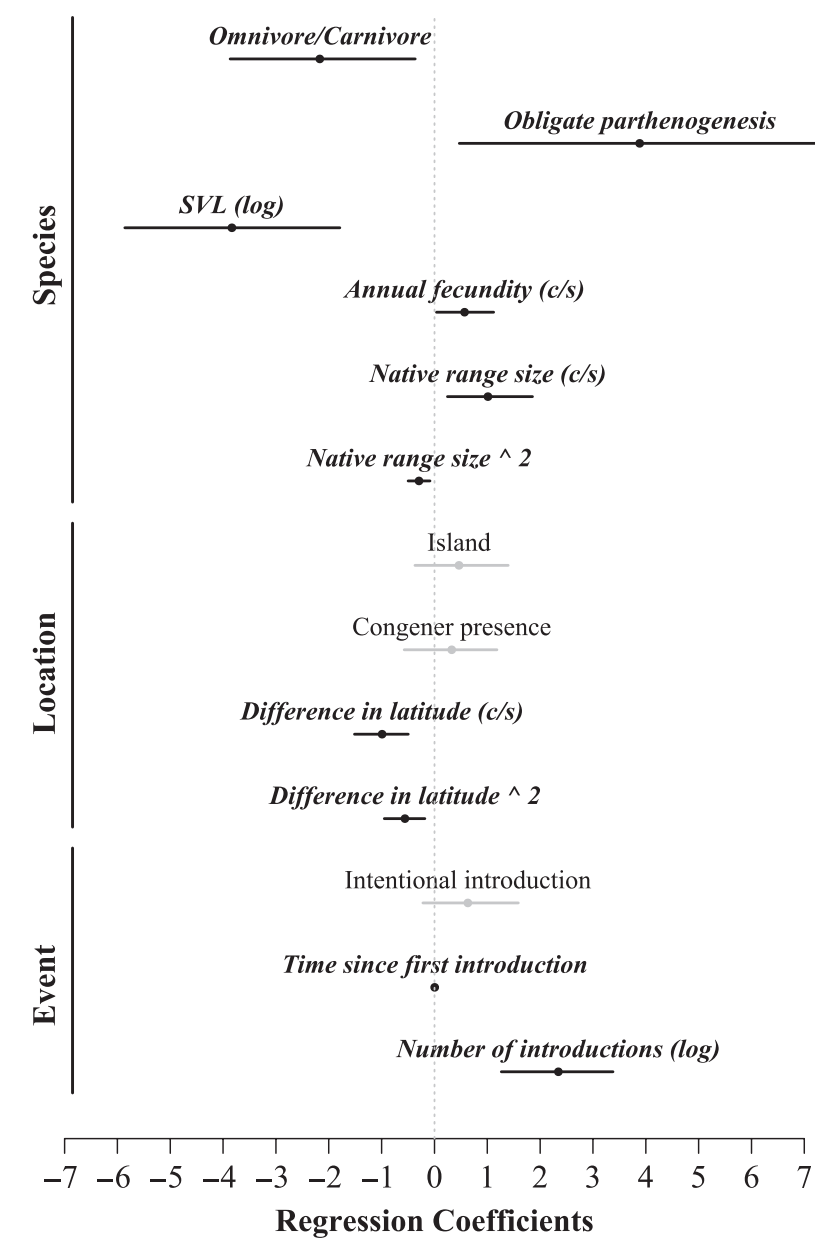

Figure 1 Coefficient estimates for the overall global model. Points correspond to posterior means with 95\% Bayesian HPD intervals. Bold points and lines indicate variables significant at $\alpha<0.05$. Species: species-level variables, Location: location-level variables and Event: event-level variables. c/s, variable centred and scaled by one standard deviation; $\log , \log _{10}$-transformed variable.

Table 4 DIC rankings of the global model, hypotheses submodels and null model from the overall analysis

\begin{tabular}{llr}
\hline Model & DIC & $\Delta$ DIC \\
\hline Overall global & 488.51 & 0.00 \\
Location level & 524.41 & 35.90 \\
Event level & 554.50 & 65.99 \\
Species level & 583.08 & 94.57 \\
Null & 593.68 & 105.17 \\
\hline
\end{tabular}

\section{DISCUSSION}

We evaluated non-native reptile establishment success in the context of event-, location- and species-level factors. Our overall conclusion hints at a scale dependency in the establishment process and highlights the primary limiting potential of environmental mismatch between native and introduced ranges (Tables $3 \& 4$ ). However, our results also clearly indicate the importance of event characteristics (e.g. number of introductions) and species traits during population establishment (Table 4; overall model) and suggest that each should be considered when estimating the risk of establishment by non-native species.

Over the course of this research, it has become clear that we are overdue for an updated literature review of the factors contributing to establishment success across taxa. Although outside the purview of this manuscript, we attempt to integrate the findings from previous work on other vertebrate taxa into a more detailed discussion of our results specific to reptiles. We recognize there are many more articles that could have been included in these comparisons, but we did not want to distract from our overall goal to describe the factors influencing reptile establishment success.

Our general conclusions regarding the importance of location-level variables agree with studies focused on reptiles regionally and amphibians globally (Bomford et al., 2009b; van Wilgen et al., 2009; Rago et al., 2012; van Wilgen \& Richardson, 2012) and indicate a significant role of climate matching and features of the introduced environment in reptile establishment success. Furthermore, the importance of location-level variables is similar to what others have found in birds (Duncan et al., 2001), mammals (Forsyth et al., 2004; Bomford et al., 2009a), crayfish (Capinha et al., 2013), freshwater fishes (Bomford et al., 2010) and other studies of reptiles (Bomford et al., 2009b). The general importance of location-level factors across taxa highlights the need to collect relevant environmental parameters for comparison between native and introduced ranges when determining the likelihood of non-native establishment success.

Despite studies showing that PET is a strong predictor of reptile richness (Currie, 1991; Rodriguez et al., 2005), our results indicated that divergence in latitude better captured environmental differences important for establishment. Although others have recommended against utilizing latitude as a surrogate for climatic variation (Hawkins \& Diniz-Filho, 2004), we argue latitude may be more appropriate than PET for analyses conducted at such large scales due to the difficulty of effectively capturing the true PET tolerances within coarsely defined native ranges (i.e. absence of finer scale PET information). Further, difference in latitude has the added benefit of being relatively simple to calculate and is likely less sensitive to error in native range estimation than other climate matching variables, particularly in the absence of finescale spatial information.

In addition, introduced reptiles were more likely to establish in the presence of congeners, further supporting Darwin's pre-adaptation hypothesis (Tingley et al., 2011; Ferreira et al., 2012b). However, after accounting for species' life history in our overall model, congener presence was no longer significant. This may be due to redundancy between some species traits and the congener variable, indicating that congener data may capture relevant life-history traits for establishment success (Thuiller et al., 2010). Importantly, this is 
contrary to the findings of van Wilgen \& Richardson (2011) where reptiles were less likely to establish in the presence of close relatives - as defined by two phylogenetic distance metrics - when introduced to California and Florida. The disparity between the two analyses may be due to differences in spatial scale or the discrete versus continuous metrics used to define relatedness. Clearly, integrating a phylogenetic component to our assessment, similar to the metrics used by van Wilgen \& Richardson (2011), would help inform the debate between Darwin's pre-adaptation and naturalization hypotheses, but unfortunately these data are lacking for a large number of species within our database. As data become available, further analyses will be required to rigorously test these hypotheses and to identify any scale dependency associated with phylogenetic relatedness in reptile establishment success.

As with previous studies on other taxa, we found event-level factors were also important drivers of non-native establishment success (Forsyth \& Duncan, 2001; Lockwood et al., 2009; Simberloff, 2009; Blackburn et al., 2013). For instance, the odds of reptile establishment increased the more often a species was introduced to a given location, similar to freshwater fishes (Bomford et al., 2010), birds (Duncan et al., 2001; Cassey et al., 2004), mammals (Forsyth et al., 2004), insects (Lester, 2005) and other studies of reptiles (van Wilgen \& Richardson, 2012). In addition, there is some indication that larger propagule size (e.g. numbers of individuals) increased the odds of establishment in crayfish (Capinha et al., 2013), fish (Marchetti et al., 2004), insects (Memmott et al., 2005) and birds (Cassey et al., 2004; Blackburn et al., 2013). If mode of introduction can serve as a surrogate for propagule size (as suggested in Kraus, 2009; Rago et al., 2012), our analyses support previous findings in reptiles (van Wilgen \& Richardson, 2012), indicating that larger introductions (i.e. intentional) are more likely to be successful than smaller introductions (i.e. unintentional; Table 3), perhaps due to the demographic consequences and extinction dynamics of small populations. Although these outcomes provide little by way of novel insight into non-native establishment, they offer further support for the need to mitigate the frequency and size of introductions, particularly at the earliest stages.

Few studies have examined the influence of time on establishment success. Time since first introduction (residence time), or the time that has elapsed between initial introduction and the year 2008, proved to be an important predictor for reptiles, with a consistent effect size across analyses (Table 3). However, in the overall model, there was some indication that this increased establishment success in the past may be driven by introductions that occurred over 500 years ago and could reflect temporal trends in biotic resistance, environmental disturbance or detection bias (past versus present).

Finally, our results support the idea that species-level characteristics are less important than climate matching or propagule pressure, but still contribute in a meaningful way to establishment success (Hayes \& Barry, 2008; Rago et al.,
2012). However, species-level characteristics that are predictive of successful introductions are likely to be taxa-specific (Sakai et al., 2001) and site-specific (Lake \& Leishman, 2004). Although few studies have found significant and consistent effects of life history on establishment success (e.g. age at sexual maturity, van Wilgen \& Richardson, 2012), we identified five contributing life-history factors in reptiles: parthenogenesis, SVL, fecundity, herbivory and native range size (Table 3).

While the positive effect of parthenogenesis on population establishment may seem intuitive, we are the first to quantitatively estimate the effect of parthenogenesis relative to other life-history, event-level and location-level factors. Interestingly, our finding is contrary to the only other analysis to incorporate parthenogenesis in an assessment of reptiles (Fujisaki et al., 2010), but this may be due to a prohibitively small sample of parthenogenetic species introductions in their local-scale analysis. In effect, species with parthenogenesis may be less sensitive to the influence of event-level factors because these species may easily overcome small initial population size. Although our analyses primarily focused on obligate parthenogenetic species due to the difficulty in identifying facultative parthenogenesis, a growing body of literature indicates that facultative parthenogenesis may be common among squamates, with varying degrees of offspring viability (Booth et al., 2012), and may provide a significant advantage to invading snakes and lizards.

In addition, we found that both smaller-bodied (i.e. adult SVL) and more fecund reptiles were more likely to succeed in establishing novel populations. Interestingly, a similar pattern in body size has been found in some fishes (Ruesink, 2005), insects (Lester, 2005) and mammals (Jeschke \& Strayer, 2006; Pereira-Garbero et al., 2013), but not in birds (Blackburn et al., 2009). Our results support the idea that smaller-bodied organisms are more successful when introduced as they are less prone to extinction (Jeschke \& Strayer, 2008; Tingley et al., 2013) and may be related to greater niche availability for smaller-bodied species (Meiri, 2008), reduced susceptibility to human-altered landscapes associated with the introduced locations, or differences in early detection by management officials. Additionally, similar to findings in birds (Cassey et al., 2014), more fecund species may have higher intrinsic population growth rates and be capable of rapid population growth despite the factors limiting small populations. Herbivores are also predicted to be more successful than omnivores and carnivores when introduced to new environments (Lever, 2003) and that is supported by findings in birds and mammals (Jeschke \& Strayer, 2006) but not in fishes (Ruesink, 2005). However, our analyses supported this prediction and may indicate that reptilian herbivores are better able to find viable food sources than species dependent upon capturing prey or that higher trophic levels are more susceptible to extinction risk (Purvis et al., 2000).

Native range size was included as a species-level variable with the idea that larger native ranges indicated species with greater environmental tolerances and thus species with larger 
native ranges may be more likely to find introduced locations suitable for establishing populations. This factor has been widely studied for plants (e.g. Hui et al., 2014), but less so for animals (e.g. Rago et al., 2012). However, native range size may also capture unmeasured variation beyond the variables we considered in our analysis but that may be relevant to non-native reptile establishment. The fact that global models supported the incorporation of native range size in addition to our other covariates suggested that there are important drivers of reptile establishment success not explicitly considered within our models, and are likely to include environmental factors or species traits correlated with native range size.

Despite our imperfect knowledge of reptile life-history traits, we identified five traits that are likely to be important predictors of establishment success in reptiles. Like other analyses that have attempted to include life-history variables as predictors of establishment success (Fujisaki et al., 2010; van Wilgen \& Richardson, 2012), we are limited by the fact that the life-history parameters we used were attained from native populations. Life-history data derived solely from native populations may be confounded with the extent of environmental overlap between native and non-native ranges; thus, some explanatory power within life-history traits could be captured by climate matching variables. This effect would be undetectable within a typical introduction data set (including ours) without demographic data from the introduced range. Interestingly, some of the most high-profile invasive reptiles are practically unstudied in their native range (e.g. Boiga irregularis and Python molurus; Fritts \& Rodda, 1998; Dorcas et al., 2012), and even fewer studies have compared life-history traits between native and introduced populations of reptiles (e.g. Rödder \& Lötters, 2009), although the high degree of plasticity in reptilian life-history traits, especially growth and reproduction, makes them ideal candidates for observing such differences.

In conclusion, we encourage more detailed data collection efforts oriented specifically at comparing life-history parameters between native and introduced populations to test more accurately the relative importance of life history in nonnative reptile establishment. In addition, a more thorough examination of the relative influence of each factor set on later stages of the invasion process is needed (e.g. rate of spread). However, our results clearly indicate the importance of halting progress during the earliest stages of an introduction, particularly for more fecund species originating from native ranges with similar climatic conditions. More can be carried out by nations or local governments to assess the extent of climate match with the native ranges of imported non-native reptiles or global trade partners to mitigate the risk of non-native reptile establishment. Once this has been accomplished, nations can then enforce regulations on the trade of high-risk species or put in place safeguards to protect against the unintentional transport of non-native species from high-risk regions of the world. Considering the potentially devastating effects of these introductions, we need to be cognizant of the factors influencing non-native establishment to mitigate future releases and facilitate the early detection of potentially invasive reptile species.

\section{ACKNOWLEDGEMENTS}

We thank F. Kraus for the database; J. Montes, E. Orning and C. Stonecipher for help with data collection; the USU Ecology Center and Utah Agricultural Experiment Station for funding; and J. Benson, M. Crump and E.D. Brodie Jr. for editorial comments.

\section{REFERENCES}

Allen, C.R., Nemec, K.T., Wardwell, D.A., Hoffman, J.D., Brust, M., Decker, K.L., Fogell, D., Hogue, J., Lotz, A., Miller, T., Pummill, M., Ramirez-Yanez, L.E. \& Uden, D.R. (2013) Predictors of regional establishment success and spread of introduced non-indigenous vertebrates. Global Ecology and Biogeography, 22, 889-899.

Barney, J.N. \& Whitlow, T.H. (2008) A unifying framework for biological invasions: the state factor model. Biological Invasions, 10, 259-272.

Bates, D., Maechler, M. \& Bolker, B. (2011) LME4: linear mixed-effects models using $S 4$ classes. $\mathrm{R}$ package version 0.999375-42 http://CRAN.R-project.org/package=lme4.

Blackburn, T.M., Cassey, P. \& Lockwood, J.L. (2009) The role of species traits in the establishment success of exotic birds. Global Change Biology, 15, 2852-2860.

Blackburn, T.M., Prowse, T.A.A., Lockwood, J.L. \& Cassey, P. (2013) Propagule pressure as a driver of establishment success in deliberately introduced exotic species: fact or artefact? Biological Invasions, 15, 1459-1469.

Bomford, M., Darbyshire, R.O. \& Randall, L. (2009a) Determinants of establishment success for introduced exotic mammals. Wildlife Research, 36, 192-202.

Bomford, M., Kraus, F., Barry, S.C. \& Lawrence, E. (2009b) Predicting establishment success for alien reptiles and amphibians: a role for climate matching. Biological Invasions, 11, 713-724.

Bomford, M., Barry, S.C. \& Lawrence, E. (2010) Predicting establishment success for introduced freshwater fishes: a role for climate matching. Biological Invasions, 12, 2559-2571.

Booth, W., Smith, C.F., Eskridge, P.H., Hoss, S.K., Mendelson, J.R. \& Schuett, G.W. (2012) Facultative parthenogenesis discovered in wild vertebrates. Biology Letters, 8, 983-985.

Capinha, C., Brotons, L. \& Anastacio, P. (2013) Geographical variability in propagule pressure and climatic suitability explain the European distribution of two highly invasive crayfish. Journal of Biogeography, 40, 548-558.

Cassey, P. (2003) A comparative analysis of the relative success of introduced land birds on islands. Evolutionary Ecology Research, 5, 1011-1021.

Cassey, P., Blackburn, T.M., Sol, D., Duncan, R.P. \& Lockwood, J.L. (2004) Global patterns of introduction effort and establishment success in birds. Proceedings of the Royal Society B-Biological Sciences, 271(Suppl.), S405-S408. 
Cassey, P., Prowse, T.A.A. \& Blackburn, T.M. (2014) A population model for predicting the successful establishment of introduced bird species. Oecologia, 175, 417-428.

Currie, D.J. (1991) Energy and large-scale patterns of animal-species and plant-species richness. The American Naturalist, 137, 27-49.

Dorcas, M.E., Willson, J.D., Reed, R.N., Snow, R.W., Rochford, M.R., Miller, M.A., Meshaka, W.E., Andreadis, P.T., Mazzotti, F.J., Romagosa, C.M. \& Hart, K.M. (2012) Severe mammal declines coincide with proliferation of invasive Burmese Pythons in Everglades National Park. Proceedings of the National Academy of Sciences USA, 109, 2418-2422.

Duncan, R.P., Bomford, M., Forsyth, D.M. \& Conibear, L. (2001) High predictability in introduction outcomes and the geographical range size of introduced Australian birds: a role for climate. Journal of Animal Ecology, 70, 621-632.

Engeman, R., Jacobson, E., Avery, M.L. \& Meshaka, W.E. Jr (2011) The aggressive invasion of exotic reptiles in Florida with a focus on prominent species: a review. Current Zoology, 57, 599-612.

Ferreira, R.B., Callahan, C.M., Poessel, S.A. \& Beard, K.H. (2012a) Global assessment of establishment success for amphibian and reptile invaders. Wildlife Research, 39, 637640.

Ferreira, R.B., Beard, K.H., Peterson, S.L., Poessel, S.A. \& Callahan, C.M. (2012b) Establishment of introduced reptiles increases with the presence and richness of native congeners. Amphibia-Reptilia, 33, 387-392.

Forsyth, D.M. \& Duncan, R.P. (2001) Propagule size and the relative success of exotic ungulate and bird introductions to New Zealand. The American Naturalist, 157, 583-595.

Forsyth, D.M., Duncan, R.P., Bomford, M. \& Moore, G. (2004) Climatic suitability, life-history traits, introduction effort, and the establishment and spread of introduced mammals in Australia. Conservation Biology, 18, 557-569.

Fritts, T.H. \& Rodda, G.H. (1998) The role of introduced species in the degradation of island ecosystems: a case history of Guam. Annual Review of Ecology and Systematics, 29, 113-140.

Fujisaki, I., Hart, K.M., Mazzotti, F.J., Rice, K.G., Snow, S. \& Rochford, M. (2010) Risk assessment of potential invasiveness of exotic reptiles imported to south Florida. Biological Invasions, 12, 2585-2596.

Hadfield, J.D. (2010) MCMC methods for multi-response generalized linear mixed models: the MCMCglmm R package. Journal of Statistical Software, 33, 1-22.

Hawkins, B.A. \& Diniz-Filho, J.A. (2004) 'Latitude' and geographic patterns in species richness. Ecography, 27, 268-272.

Hayes, K.R. \& Barry, S.C. (2008) Are there any consistent predictors of invasion success? Biological Invasions, 10, 483-506.

Hui, C., Richardson, D.M., Visser, V. \& Wilson, J.R.U. (2014) Macroecology meets invasion ecology: performance of Australian acacias and eucalypts around the world revealed by features of their native ranges. Biological Invasions, 16, 565-576.
Jeschke, J.M. \& Strayer, D.L. (2005) Invasion success of vertebrates in Europe and North America. Proceedings of the National Academy of Sciences USA, 102, 7198-7202.

Jeschke, J.M. \& Strayer, D.L. (2006) Determinants of vertebrate invasion success in Europe and North America. Global Change Biology, 12, 1608-1619.

Jeschke, J.M. \& Strayer, D.L. (2008) Are threat status and invasion success two sides of the same coin? Ecography, 31, 124-130.

Kearney, M., Fujita, M.K. \& Ridenour, J. (2009) Lost sex in the reptiles: constraints and correlations. Lost sex: the evolutionary biology of parthenogenesis (ed. by I. Schön, K. Martens and P. Van Dijk), pp. 447-474. Springer, Dordrecht, Holland.

Kolar, C. \& Lodge, D. (2001) Progress in invasion biology: predicting invaders. Trends in Ecology and Evolution, 16, 199-204.

Kraus, F. (2009) Alien reptiles and amphibians: a scientific compendium and analysis series. Springer, Dordrecht.

Lake, J.C. \& Leishman, M.R. (2004) Invasion success of exotic in natural ecosystems: the role of disturbance, plant attributes and freedom from herbivores. Biological Conservation, 117, 215-226.

Lester, P.J. (2005) Determinants for the successful establishment of exotic ants in New Zealand. Diversity and Distributions, 11, 279-288.

Lever, C. (2003a) Naturalized reptiles and amphibians of the world. Oxford University Press, New York, NY, USA.

Lockwood, J.L., Cassey, P. \& Blackburn, T. (2005) The role of propagule pressure in explaining species invasions. Trends in Ecology and Evolution, 20, 223-228.

Lockwood, J.L., Cassey, P. \& Blackburn, T.M. (2009) The more you introduce the more you get: the role of colonization pressure and propagule pressure in invasion ecology. Diversity and Distributions, 15, 904-910.

Mack, R., Simberloff, D., Londsdale, W.M., Evans, H., Clout, M. \& Bazzazz, F.A. (2000) Biotic invasions: causes, epidemiology, global consequences, and control. Ecological Applications, 10, 689-710.

Marchetti, M.P., Moyle, P.B. \& Levine, R. (2004) Alien fishes in California watersheds: characteristics of successful and failed invaders. Ecological Applications, 14, 587-596.

Meiri, S. (2008a) Evolution and ecology of lizard body sizes. Global Ecology and Biogeography, 17, 724-734.

Memmott, J., Craze, P.G., Harman, H.M., Syrett, P. \& Fowler, S.V. (2005) The effect of propagule size on the invasion of an alien insect. Journal of Animal Ecology, 74, 50-62.

Myhrvold, N.P., Baldridge, E., Chan, B., Freeman, D.L. \& Ernest, S.K.M. (2014) An amniote life history database to perform comparative analyses with birds, mammals, and reptiles. Dryad Digital Repository, doi:10.5061/dryad.t6 m96.

Pereira-Garbero, R., Barreneche, J.M., Laufer, G., Achaval, F. \& Arim, M. (2013) Invasive mammals in Uruguay, history, perspectives and consequences. Revista Chilena De Historia Natural, 86, 403-421. 
Poessel, S.A., Beard, K.H., Callahan, C.M., Ferreira, R.B. \& Stevenson, E.T. (2013) Biotic acceptance in introduced amphibians and reptiles in Europe and North America. Global Ecology and Biogeography, 22, 192-201.

Purvis, A., Gittleman, J.L., Cowlishaw, G. \& Mace, G.M. (2000) Predicting extinction risk in declining species. Proceedings of the Royal Society B-Biological Sciences, 267, 1947-1952.

Rago, A., While, G.M. \& Uller, T. (2012) Introduction pathway and climate trump ecology and life history as predictors of establishment success in alien frogs and toads. Ecology \& Evolution, 2, 1437-1445.

R Development Core Team (2012) R: A language and environment for statistical computing. R Foundation for Statistical Computing, Vienna, Austria. ISBN 3-900051-07-0, URL http://www.R-project.org/

Rödder, D. \& Lötters, S. (2009) Niche shift versus niche conservatism? Climatic characteristics of the native and invasive ranges of the Mediterranean house gecko (Hemidactylus turcicus). Global Ecology and Biogeography, 18, 674-687.

Rodriguez, M.A., Belmontes, J.A. \& Hawkins, B.A. (2005) Energy, water and large-scale patterns of reptile and amphibian species richness in Europe. Acta OecologicaInternational Journal of Ecology, 28, 65-70.

Rogers, H., Hille Ris Lambers, J., Miller, R. \& Tewksbury, J.J. (2012) 'Natural experiment' demonstrates top-down control of spiders by birds on a landscape level. PLoS ONE, 7, e43446.

Ruesink, J.L. (2005) Global analysis of factors affecting the outcome of freshwater fish introductions. Conservation Biology, 19, 1883-1893.

Sakai, A.K., Allendorf, F.W., Holt, J.S., Lodge, D.M., Molofsky, J., With, K.A., Baughman, S., Cabin, R.J., Cohen, J.E., Ellstrand, N.C., McCauley, D.E., O’Neil, P., Parker, I.M., Thompson, J.N. \& Weller, S.G. (2001) The population biology of invasive species. Annual Review of Ecology and Systematics, 32, 305-332.

Simberloff, D. (2009) The role of propagule pressure in biological invasions. Annual Review of Ecology Evolution and Systematics, 40, 81-102.

Sol, D., Vila, M. \& Kuhn, I. (2008) The comparative analysis of historical alien introductions. Biological Invasions, 10, 1119-1129.

Spiegelhalter, D.J., Best, N.G., Carlin, B.P. \& Van Der Linde, A. (2002) Bayesian measures of model complexity and fit. Journal of the Royal Statistical Society: Series B (Statistical Methodology), 64, 583-639.

Thuiller, W., Gallien, L., Boulangeat, I., de Bello, F., Munkemuller, T., Roquet, C. \& Lavergne, S. (2010) Resolving Darwin's naturalization conundrum: a quest for evidence. Diversity and Distributions, 16, 461-475.

Tingley, R., Phillips, B.L. \& Shine, R. (2011) Establishment success of introduced amphibians increases in the presence of congeneric species. The American Naturalist, 177, 382388.
Tingley, R., Hitchmough, R.A. \& Chapple, D.G. (2013) Lifehistory traits and extrinsic threats determine extinction risk in New Zealand lizards. Biological Conservation, 165, 62-68. Trabucco, A. \& Zomer, R. (2009) Global aridity index (global-aridity) and global potential evapo-transpiration (globalpet) geospatial database CGIAR Consortium for spatial information. Published online, available from the CGIAR-CSI GeoPortal at: http://www.csi.cgiar.org.

Traveset, A. \& Riera, N. (2005) Disruption of a plant-lizard seed dispersal system and its ecological effects on a threatened endemic plant in the Balearic Islands. Conservation Biology, 19, 421-431.

Uetz, P. \& Hallermann, J. (2008a) The TIGR reptile database. http://reptile-database.org/

van Wilgen, N.J. \& Richardson, D.M. (2011) Is phylogenetic relatedness to native species important for the establishment of reptiles introduced to California and Florida? Diversity and Distributions, 17, 172-181.

van Wilgen, N.J. \& Richardson, D.M. (2012) The roles of climate, phylogenetic relatedness, introduction effort, and reproductive traits in the establishment of non-native reptiles and amphibians. Conservation Biology, 26, 267277.

van Wilgen, N.J., Roura-Pascual, N. \& Richardson, D.M. (2009) A quantitative climate-match score for risk-assessment screening of reptile and amphibian introductions. Environmental Management, 44, 590-607.

\section{SUPPORTING INFORMATION}

Additional Supporting Information may be found in the online version of this article:

Data S1 The complete datafile used to analyze global establishment success of non-native reptiles.

Appendix S1 Metadata for the reptile invasion database.

Appendix S2 References used to compile the invasion database.

\section{BIOSKETCH}

The research team was brought together by a shared interest in conservation and global, non-native reptile establishment success.

Author contributions: P.M., K.B. and A.D. collected data and contributed equally to the writing. K.B. conceived the idea. P.M. completed the analyses and coordinated the writing. A.T. coordinated the data management and provided valuable comments. L.L., R.K., N.N., D.K. and H.M collected data and provided valuable comments.

Editor: David Richardson 